\title{
Comparative analysis of intergenerational educational mobility in Spain and Mexico ${ }^{1}$
}

DOI: https://doi.org/10.32870/dse.v0i12.263

César Augusto Ricardi Morgavi*

(Trad. Marcela Suárez Essport)

\begin{abstract}
This article presents a compared perspective analysis of the absolute and relative intergenerational educational mobility in the Mexican and Spanish societies. Educational reproduction and upward and downward mobility are analyzed working from transition matrixes of educational mobility, with and without the integration of the temporal factor of the birth cohorts. The levels of educational ascription through inherited positions, and the degrees of educational permeability in both countries are analyzed; relative, structural and replacement educational mobility is also studied through the compared evaluation of loglinear models applied to the study of educational mobility in a context of educational expansion, subsequent economic crisis and reduction of public expense in education. Keywords: educational mobility, reproduction, birth cohorts, Spain, Mexico
\end{abstract}

\section{Introduction}

The present article addresses the theme of intergenerational educational mobility in Spain and Mexico based on a comparative approximation which integrates the analysis of absolute and relative educational mobility from transition matrixes and log-linear models. Educational mobility refers in this study to the existing mobility between generations, that is, the existing mobility between the origins (O) (the parents' educational level) ${ }^{2}$ and the educational destinies (D) (their sons/daughters educational level) in the societies under study. While the absolute intergenerational educational mobility is the result of crossing the educational origin $(\mathrm{O})$ with the educational position of destiny (D), which allows to describe and analyze the mobility in two different moments, the relative intergenerational educational mobility, or educational fluidity, shows the level of opening-closing of the educational stratification in a given society, and for a given period of time, through the study of the degree of independence between origins and destinies in the mobility table. In general, educational mobility must be understood as the hierarchic upward or downward leap of individuals from one educational category to another in the structure of educational stratification. Its study, which implies knowledge of educational upward and downward mobility as well as educational immobi-

${ }^{1}$ This article is a result of a research in process carried out by the author who writes about occupational and educational mobility from a comparative perspective for a cluster of countries from Europe and Latin America.

${ }^{2}$ This article considers the education level of the father as the level of education of the parents, that is, as the educational origin (O) of sons/daughters.

*PhD candidate (University of Barcelona, Spain, and University of Guadalajara, Mexico. E-mail: sociologicalthinktanblog@ gmail.com 
lity (inherited positions) between parents and their sons/daughters calls for the application of the International Standard Classification of Education (ISCED). ${ }^{3}$

The analysis of the intergenerational educational mobility comprises the study of structural educational mobility, which refers to the educational mobility between parents and their sons/ daughters due to the changes that have taken place in the educational and/or demographic structure, and the analysis of the replacement mobility, which corresponds to the rest of the educational mobility observed in the table and isolates the effects of the structural changes. The analysis of relative mobility in terms of the grade and nature of educational fluidity, together with the analysis of absolute mobility, proves appropriate in showing the total percentage of individuals whose categories of origin and destiny are different; that is, about the knowledge of the total educational mobility, as well as the distribution of the different educational origins of the individuals in the same category of destiny (inflow mobility), and the behavior of the inter-cohort evolution of the mobility patterns.

The comparative analysis of the levels of educational mobility in the societies of Mexico and Spain are of special interest inasmuch as it can be seen that a high margin of the inequality in Latin America is explained, on one hand, by the "differential returns to different levels of education, in particular the elevated returns to higher education" (Beyer and Le Foulon 2002, and Duryea and Pages 2002, cited in Torche, 2007), which "might have increased in the last two decades in the context of the economic liberalization experienced [in Mexico]"4 (Cragg and Epelbaum 1966, and Robins 1995, at Torche, 2007: 6), and on the other because education "plays two conflicting roles in the transmission of social advantages and disadvantages along time [as it constitutes] the main mediating mechanism of social origin advantages [and] the main source of independent welfare of social origin by creating mobility opportunities" (Torche, 2007: 6). This is meant to indicate that parents with higher resources, who form part of the educational capital, invest more in education for their sons/daughters, thus expanding their initial comparative advantages and their possibilities to achieve economic welfare in their adult life. A close attention to Torche's (n.d.) work leads to opening the question of why it is relevant to go deeper on the study of education and formation based on the analysis of educational mobility.

One could answer that, in the first place: because of an "efficiency" criterion, in second place, because of a "normative reasons" criterion, and in third place, because of a "social integration" criterion. Efficiency, because an educationally immobile society which does not provide social mobility opportunities to individuals coming from low socioeconomic resource origins will not be ca-

${ }^{3}$ The ISCED classification levels applied in the analysis are: below the lower secondary level (ISCED 0-1), secondary lower level completed (ISCED-2), higher secondary level completed (ISCED-3), post-secondary non-tertiary educational level completed (ISCED-4) and tertiary educational level completed (ISCED-5-6).

${ }^{4}$ For a better understanding of the relationship of determination between high economic returns to university education level and economic well-being in contemporary global societies and in Latin America, see Birdsall and Lodoño (1997), Cragg and Epelbaum (1996) and Psacharopoulos and Patrinos (2002). 
pable of improving the use of their existing human resources and talents, keeping their members in a level below their optimal capacities (Torche, n.d.). Normative reasons, because the relevance of studying educational mobility lies in having a better knowledge of the strength of the educational origins in the educational success and the future welfare of individuals, which must be considered a matter of social justice (Torche, n.d.). Social integration, in the sense that an educationally immobile society characterized by the rigidity of their educational mobility structure, erodes legitimacy and social integration, as well as social cohesion, social tissue and its regeneration.

\section{What is Important to Know (The Problematization of Educational Mobility)}

This article provides information on the ways in which the opportunities for educational mobility are distributed among generations, at a given moment and along time (cohort analysis). Common and differentiated patterns of intergenerational educational mobility are identified through the analysis of probabilistic samples. In the case of Spain the information obtained is the result of a multistage stratified probabilistic sampling with a sampling error of $5 \%$ and $n=1244$. In the case of Mexico the information was obtained through a sampling of conglomerates and multistage selection with a maximum expected absolute error of \pm 3 percentage points and $n=6531$. The information comes from two databases: the European Social Survey (ESS) 2010 for Spain, and the Social Mobility Survey 2011 (Encuesta de Movilidad Social, EMOVI) for Mexico.

The driving questions of the investigation are: What are we talking about in the field of sociology that studies social mobility when we refer to intergenerational educational mobility in Spain and Mexico? Therefore, what new information can be contributed to the knowledge of these two societies from the comparative examination of the mobility tables and the explanatory models of the relative educational mobility? Is it possible to claim the existence of a persistent educational mobility pattern through generations in the cases of Spain and Mexico? Does the pattern inform of a variable or invariable mobility along time? Do Mexican and Spanish societies come closer or move apart from each other in terms of equity of opportunities for educational mobility?

\section{State of the Art (Discussions)}

The analysis developed in this article is motivated by the fact that investigating absolute and relative intergenerational educational mobility in the contexts of the Mexican and Spanish societies contributes to filling a current knowledge gap. Sánchez (2004: 3) states that the number of authors interested in the study of the relative intergenerational educational mobility continues to be reduced, as compared to the number of authors and the attention given to the study of occupational and income relative mobility in Spain. The author is aware that there is a deficit in the production of accumulated knowledge on educational mobility in Spain in terms of longitudinal and quantitative research (Sánchez, 2004). 
When Sánchez identifies the existence of a gap in the production of knowledge on educational mobility in Spain, she is pointing at the tangential character of the study of this kind of social mobility in more extensive studies of social occupational mobility for the Spanish society. Likewise, the study of relative intergenerational social mobility in Spain is inspired by approaches of income inequity, rent or occupational status rather than by those of distribution of educational opportunities for mobility. On the sidelines of the above, substantial contributions can be identified to the field of study of social mobility for the case of Spain, among which, for the years previous to the nineties, the works of Sánchez López (1961), Lipset and Bendix (1963), Linz and Amando De Miguel (1963, 1966a, 1966b), Amando De Miguel (1965, 1966), Orizo (1965), Pinilla de las Heras (1965, 1979), Blanc (1966), the Foessa reports (1970, 1975, 1983), and Carabaña (1983) (cited in Ricardi 2012) must be included.

Towards the nineties the theme of educational mobility acquire centrality and a series of relevant publications contributed to include it in the sociological analysis, though it continues to be made in a tangential way without constituting a backbone theme of the analysis. Among these contributions stand apart those of Cachón Rodríguez (1989), Amando de Miguel (1992,1994, 1995), Jesús de Miguel (1998), Carabaña (1999), Echeverría Zabalza (1999), Cantó (2000), the Foessa report (2000), Prieto-Rodríguez and Salas (2002), and Ayala Sastre (2002), cited in Ricardi (2012).

More recently, studies like those of Calero $(2006)$, and Calero et al. $(2007,2008)$ have addressed the analysis of educational mobility in Spain, with particular emphasis on the analysis of the relative educational mobility through the application of statistical association measures and $\log$-linear models for two or more variables. Added to these is the investigation developed by Martínez-Celorrio and Marín Saldo (2010), which analyses intergenerational educational mobility in terms of relative inequality of opportunities for the Catalonian society compared with the Spanish one and a selection of other European societies. In a somehow more collateral way, Mediavilla and Calero (2010) adopt an approach based on the reproduction of educational inequalities to address attention to the comparative study of the educational mobility in six countries (Argentina, Brazil, Chile, Mexico, Peru and Venezuela) and introduce punctual observations on the behavior of the mobility patterns among those countries and the developed ones. However, their study doesn't go into details by comparing the Latin American cases and those of the countries with an advanced economy (in their study, Spain and the United States), not allowing to clearly outline the differences in educational mobility among them.

In Mexico there have been successful initiatives, such as the one developed by the Centro de Estudios Espinosa Yglesias (CEEY). The study of social mobility in the Mexican case has been mainly related to the dynamics that prevail in the labor market, such is the case of the analysis developed by Escobar $(1993,1995)$ and Escobar and Cortés (2002). These studies form part of the analytic systemic level mobility studies rather than those of institutional or structural kind, which allow starting from a more comprehensive concept about the labor market, seen as a strong condi- 
tioning and determining factor of the social structure. This form of approaching the phenomenon was influenced by a Mexican conjuncture characterized by the economic neoliberal restructuring, that took place in the eighties and was intensified in the nineties (Boado, 2008).

The empiric approach to social mobility in Mexico was influenced in some cases, which are relevant for this study, by authors coming from the theory of similarity among nations. Such is the case of Escobar's (1995) first work, in which he analyses mobility as social reproduction through patterns of relative advantages (odds ratio) and disparity rates. In this case Escobar adopts the intergenerational and intragenerational mobility analysis developed by Goldthorpe in his study of 1980 , applied to the occupational social mobility of workers in different strata living in the Guadalajara metropolis in Mexico. It may be objected that Escobar's study does not include the analysis of intergenerational educational mobility or a more detailed examination of the regime of the social occupational mobility. However, it is thanks to his study that we have access to the knowledge of the effect generated by the macroeconomic changes on the individual's occupational achievements, as well as to the form in which differences in the intragenerational mobility among occupational strata act in relation to the economic growth and crisis cycles. The dependence of differences in relation to economic cycles becomes more intense in Mexico when transversal explicative variables, such as gender variable, are integrated (Boado, 2008).

In an analogous way to what has been described for the case of Spain, the academic production of social mobility in Mexico has focused on the production of knowledge related to intergenerational and intragenerational educational mobility. Recently, there have been substantive contributions to the study of educational mobility, notably that of Torche (2007), which includes a comparative analysis of social mobility in Mexico and Chile that integrates the economic welfare mobility, the subjective mobility (perceived), and the educational mobility, as well as an analysis of the educational homogamy in both countries. The point of departure of the analysis is the influence of inequality on the social cohesion due to the conditioning of educational and economic welfare opportunities through the resources held by the previous generation or, what the author calls "cradle accidents" Torche, (2007: 2).

Torche's (2007) analysis provides a finding based on the evidence of the presence of an educational mobility pattern shared by Mexico and Chile, which is characterized by strong barriers to ascending educational mobility towards higher educational levels, which can be interpreted as a strong intergenerational reproduction of positions at the top of the educational structure. The comparative analysis among countries with an advanced economy are prone to conclude that this pattern is a distinctive trait of Latin American societies, which make Mexico and Chile interesting cases for the development of international comparative analysis of social mobility.

The author points out that in the case of Mexico, the progress in educational mobility is more modest than the one observed in the Chilean one, which can be explained to some extent by the scarcity of specific databases on the social mobility with representation at a national level. What 
we know at this moment comes from intergenerational mobility analysis based on urban samplings, implying that in Mexico, as well as in Chile, there has been an increase in the level of incidence of the resources of origin in the educational achievement of individuals during the eighties, while information that would allow the analysis for recent years is still required (Torche, 2007: 5).

Torche's analysis of educational mobility in Mexico includes an analysis of the absolute educational mobility as well as one of the relative educational mobility. From these analysis arises the fact that the high inequality that characterizes the region is explained by the existing differentials in economic capital returns, which are at the same time related to the educational levels achieved and in particular by the access and completion of higher educational levels (university-based and nonuniversity based post-secondary education). Furthermore, it is concluded that education is a mediating factor between disadvantages of origin and economic and educational achievement of the adult individual, since the more resources held by the parents the more they invest in their progeny's education, resulting in greater economic welfare advantages for their offspring. Additionally, based on the carried out analysis, it is possible to ascertain that for the case of Mexico, education as a capital conforms a welfare source relatively independent from the resources of social origin. In a complementary analysis to the recently described, Torche (n.d.) goes back to the examination of intergenerational educational mobility in Mexican society to see further into the study of change in the mobility regime through time. Even if in his comparative analysis of educational mobility between Mexico and Chile (Torche, 2007), the temporal change was studied from the variable of birth cohorts based on only three different moments (cohorts). Upon opening the analysis to four moments (cohorts), Torche increases his precision interpreting the results obtained with the application of log-linear models to the analysis of mobility, in particular the "crossing" model-the only one applied in the analysis of his article of 2007-supplemented with the application of constant fluidity and uniform difference (unidiff) models.

\section{The Absolute Educational Mobility in Spain}

\section{Educational Upward and Downward Mobility and Reproduction in Spain}

The following analysis goes through the educational upward and downward mobility and reproduction levels between educational origins and destinies of Spaniards between 25 and 65 years old. The proportion of educational upward mobility in a society is obtained by adding together the observed percentages in the educational mobility table positioned below the diagonal line. The proportion of the educational downward mobility is obtained by adding together the observed percentages in the educational mobility table positioned above the diagonal line. The proportion of the educational reproduction or inheritance is obtained by adding together the observed percentages positioned in the diagonal in the educational mobility table (clear grey in Table 1). The first thing to be appreciated in the case of Spanish society is that the educational upward mobility, that is, 
the overcoming of the parents' educational level by their sons/daughters is $60.3 \%$ (Table 1). The educational downward mobility, which entails the opposite situation, that is, the not overcoming the parents' educational level by their sons/daughters, is equal to $4.6 \%$ (Table 1). Meanwhile, educational reproduction, that is, the preservation of the parents' educational level by their sons/ daughters, is equal to $35.1 \%$ (Table 1). A first finding based on the observed percentages confirms that this society shows a very "fluid" educational mobility for the age range (25-65 years old) of the population under study, with a total absolute educational mobility rate (upward plus downward mobility) equals $64.9 \%$, conformed largely by movements of upward kind.

Table 1. Relation between parent and sons/daughters level of education (absolute and relative frequencies)

\begin{tabular}{|c|c|c|c|c|c|c|c|c|}
\hline \multirow{2}{*}{\multicolumn{3}{|c|}{ Spain }} & \multicolumn{5}{|c|}{ Sons/daugthers educational level (destiny) } & \multirow[b]{2}{*}{ Total } \\
\hline & & & ISCED 5-6 & ISCED 4 & ISCED 3 & ISCED 2 & ISCED 0-1 & \\
\hline \multirow{10}{*}{ 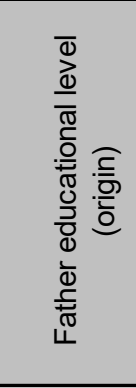 } & ISCED 5-6 & Count & 106 & 11 & 15 & 6 & 0 & 138 \\
\hline & & $\%$ of the total & 8.5 & 0.9 & 1.2 & 0.5 & 0 & 11.1 \\
\hline & ISCED 4 & Count & 16 & 3 & 3 & 3 & 1 & 26 \\
\hline & & $\%$ of the total & 1.3 & 0.2 & 0.2 & 0.2 & 0.1 & 2.1 \\
\hline & ISCED 3 & Count & 27 & 8 & 8 & 5 & 3 & 51 \\
\hline & & $\%$ of the total & 2.2 & 0.6 & 0.6 & 0.4 & 0.2 & 4.1 \\
\hline & ISCED 2 & Count & 59 & 19 & 29 & 39 & 10 & 156 \\
\hline & & $\%$ of the total & 4.7 & 1.5 & 2.3 & 3.1 & 0.8 & 12.5 \\
\hline & ISCED 0-1 & Count & 153 & 71 & 112 & 256 & 281 & 873 \\
\hline & & $\%$ of the total & 12.3 & 5.7 & 9.0 & 20.6 & 22.6 & 70.2 \\
\hline \multirow[t]{2}{*}{ Total } & & Count & 361 & 112 & 167 & 309 & 295 & 1244 \\
\hline & & $\%$ of the total & 29.0 & 9.0 & 13.4 & 24.8 & 23.7 & 100 \\
\hline
\end{tabular}

Source: Prepared by the author based on the European Social Survey, 2010.

Upon a second order of observation it can be verified that the greater percentage of educational reproduction $(22.6 \%)$ takes place in the educational level of those who have not overcome successfully the first cycle of secondary education, that is, those who have only reached an equivalent level to complete primary education, that in the ISCED classification corresponds to the ISCED 0-1 category. The educational reproduction in ISCED $0-1$ represents $64.4 \%$ of the total absolute volume of educational reproduction, while the one between parents and sons/daughters who have successfully overcome tertiary education ISCED 5-6 (8.5\%) represents $24.2 \%$ of the total absolute volume of educational reproduction. The educational reproduction in Spain tends to concentrate on educational levels at the extremes of the educational structure, forming a sort of "closed circuits" of inheritance educational positions which are stronger in the lowest level (ISCED 0-1) than in the highest one (ISCED 5-6) (Table 1).

On a third level of observation, it can be seen that out of the total educational upward mobility experimented by the sons/daughters of Spanish parents $(60.3 \%)$ those coming from parents with an ISCED 0-1 educational level show the greatest upward mobility (47.6\%) equivalent to $79 \%$ of the total volume of the educational ascent (Table 1). It is important to stress the finding that of the total educational upward mobility shown by the sons/daughters of parents of ISCED 0-1 educational 
level, it is towards the proximate position of the secondary lower level completed (ISCED 2) that the largest proportion of ascendant mobility is experienced (20.6\%), equivalent to $43.3 \%$ of the total absolute volume of educational upward mobility from the origin ISCED 0-1. Next is the upward mobility which takes place towards the tertiary educational level completed (ISCED 5-6) (12.3\%), equivalent to $25.8 \%$ of the total absolute volume of educational upward mobility from an ISCED $0-1$ origin. It must be emphasized that there is a high proportion of upward mobility experienced by the sons/daughters of parents with an educational level under the lower secondary completed (ISCED 0-1) which takes places towards the two proximate categories that bear correspondence with the secondary lower level completed (ISCED 2) and higher secondary level completed (ISCED 3). Altogether they comprise $29.6 \%$ of the educational upward mobility, equivalent to $62.1 \%$ of the total absolute volume of educational upward mobility from the origin (ISCED 0-1) (Table 1)

In relation to the educational downward mobility, it is observed that the sons/daughters of parents with educational level of ISCED 5-6 experience the greatest downward mobility (2.6\%), equivalent to $56.5 \%$ of the total absolute volume of educational downward mobility from level ISCED 5-6 (Table 1). It is relevant to note that the greatest proportion of the total absolute volume of educational downward mobility registered by the sons/daughters of parents with educational level of ISCED 5-6 takes place towards the two proximate lower educational positions, the higher secondary level completed (ISCED 3) (1.2\%), equivalent to $46.1 \%$ of the total absolute volume of educational downward mobility from the ISCED 5-6 origin, and that of post-secondary non-tertiary educational level completed (ISCED 4$),(0.9 \%)$ equivalent to $34.6 \%$ of the total absolute volume of educational downward mobility from the origin ISCED 5-6 (Table 1). It should be noticed that the downward mobility experienced by the sons/daughters of parents with an educational level of ISCED 5-6 towards an educational position at the opposite lower extreme of the educational structure (ISCED 0-1) is non-existent.

By analyzing the educational inflow mobility, that is, the percentage of sons/daughters that share destiny but come from different educational origins, it is confirmed that the probability of the first ones to reach a tertiary educational level completed (ISCED 5-6) is influenced by the parents' educational levels, while a positive relation between the probability and the force of influence of the educational origins is not evident. In contrast, the analysis of inflows shows that the probability for the sons/daughters of overcoming the two lowest levels of the educational structure (ISCED 0-1 and ISCED 2) show a positive relation, namely, the higher the educational level reached by the father, the higher the probabilities for the sons/daughters to overcome the two lowest educational levels (Graphic I). 


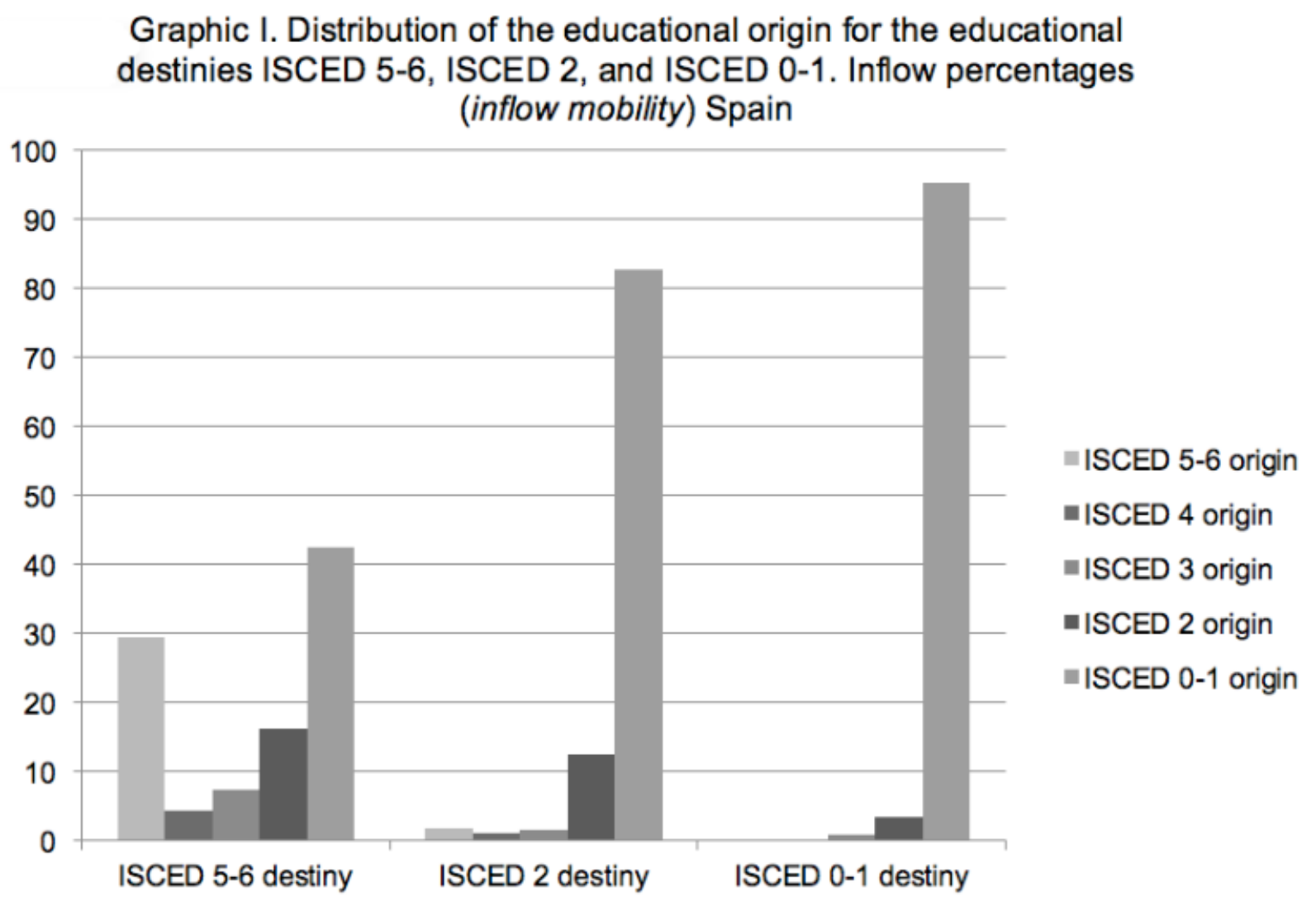

Source: Prepared by the author based on the European Social Survey, 2010.

Inter-cohort Evolution of Educational Upward and Downward Mobility and Reproduction in Spain The analysis of educational upward and downward mobility as well as reproduction becomes more accurate with the inclusion of the temporal variable of the birth cohorts. In the case of the Spanish society three birth cohorts are defined. An old cohort comprising individuals born between 1935 and 1950 who by $2010^{5}$ are between 60 and 75 years old. An intermediate cohort comprising individuals born between 1951 and 1975, who by 2010 are between 59 and 35 years old, and a young cohort comprising individuals born between 1976 and 1986, who by 2010 are between 34 and 24 years old.

The analysis of reproduction and educational mobility in the oldest birth cohort (1935-1950) shows an educational reproduction (72.6\%) above the upward mobility $(24.4 \%)$, which is the lowest level of the inter-cohort evolution, as well as in regards to the downward mobility (3\%), which is also the lowest of the inter-cohort evolution (Table 2). As compared to the two younger

\footnotetext{
${ }^{5}$ Year in which concludes the collection of information for the survey used for the analysis of educational mobility in Spain.
} 
cohorts the old cohort shows the highest level of educational reproduction, which makes evident the strong influence of the origins on the educational destinies in terms of inherited educational positions. As a consequence, the old cohort shows the lowest educational permeability in the intercohort comparison, represented by a total absolute educational mobility rate of $27.4 \%$.

Table 2. Dimensions of educational absolute mobility

\begin{tabular}{|l|r|r|r|}
\hline Spain & $1935-1950$ & $1951-1975$ & $1976-1986$ \\
\hline Inheritance & $72.6 \%$ & $35.6 \%$ & $27.2 \%$ \\
Upward & $24.4 \%$ & $61.0 \%$ & $65.9 \%$ \\
Downward & $3.0 \%$ & $3.4 \%$ & $6.9 \%$ \\
& $100.0 \%$ & $100.0 \%$ & $100.0 \%$ \\
\hline
\end{tabular}

Source: Prepared by the author based on the ESS, 2010.

In the intermediate cohort (1951-1975), and in regard to the oldest cohort, the educational reproduction $(35.6 \%)$ shows a decline of 37 percentage points, an educational upward mobility (61\%) which is increased in 36.6 percentage points and an educational downward one experiencing a slight increase from $3 \%$ to $3.4 \%$. The proportion in which the educational reproduction decrease from the old to the intermediate cohort has a stronger impact on the volume of variation of the educational upward mobility than in that of the downward one. The educational ascription, that is, the influence of the origins on the educational destinies in terms of inherited educational positions, is notably reduced in the intermediate cohort regarding the old one, which entails an increase in the educational permeability expressed by a total absolute educational mobility rate which moves from $27.4 \%$ to $64.4 \%$ (Table 2 ).

In the young cohort (1976-1986) and in regard to the intermediate cohort, the educational reproduction decreases 8.4 percentage points stablishing an inter-cohort decreasing pattern of educational reproduction $(72.6 \%, 35.6 \%$ and $27.2 \%$, respectively). The educational upward mobility in the young cohort, in regard to the intermediate, increases 4.9 percentage points, which defines an incremental educational upward mobility pattern in the inter-cohort evolution $(24.4 \%, 61 \%$ and $65.9 \%$, respectively). The educational downward mobility shows an increase of 3.5 percentage points in the young cohort in regard to the intermediate, closing a pattern of slight increases in the inter-cohort evolution ( $3 \%, 3.4 \%$ and $6.9 \%$, respectively). In the youngest cohort the educational ascription by inherited positions is weakened, being the lowest registered in the inter-cohort comparative $(27.2 \%)$, while the educational permeability increases, representing the highest total absolute educational mobility rate among cohorts $(27.4 \%, 64.4 \%$ and $72.8 \%$, respectively) (Table2).

\section{Structural and replacement educational mobility in Spain}

The absolute intergenerational educational mobility is divided in two parts, namely, structural mobility and replacement mobility; the latter also called individual or circulatory mobility. The 
structural mobility is defined as the minimal mobility required equaling the difference between the marginal of origin and the marginal of destiny. It is "the percentage of individuals that should be changed in order to equal the distributions" (Carabaña, 1999: 28), and is calculated by dividing into two the total of the absolute differences between the marginal distribution of origin $(\mathrm{O})$ and those of the distribution of destiny (D). The results are the same as the ones obtained through Duncan's dissimilarity index. The rest of the mobility, which includes the mobiles of the interior of the transition matrix, is considered replacement mobility. This mobility allows evaluating more accurately the degree of openness of the educational structure in order to reward the successful practices or the failure in the competence for the upward mobility to higher educational positions. The replacement mobility can be considered as an indicator of what in the analysis of the educational mobility is called "permeability" of the educational structure (see Filgueira, 2001:16).

The structural mobility allows familiarizing with the degree of openness of educational structure without isolating (controlling) the movements encouraged by changes in the educational and demographic structures. In the case of the Spanish society the structural educational mobility is equal to $46.5 \%$ and the replacement mobility, which isolates (controls) the changes in the educational and demographic structure, is of $18.4 \%$ (Table 6). These percentages speak of low levels of rigidity in the educational stratification system, which entail a greater possibility that those educational positions in the different educational levels be filled according to merits and performance capacity, which is equivalent to stating that the influence of the educational origin on the mobility towards different educational positions experienced by the new generation is reduced, being in turn the qualifications, capacity and performance what promote the reached academic achievements.

\section{Inter-cohort Evolution of Structural and Replacement Educational Mobility in Spain}

In the previous section we examined the record of the structural and replacement educational mobility for the Spanish case in individuals between 25 and 65 years old without including any temporal differentiation at all. Upon including the time factor by means of the birth cohorts variables (old cohort 1935-1950, intermediate cohort 1951-1975 and young cohort 1976-1986) it is confirmed that in the old cohort - individuals who started their educational experience between 1942 and 1957 the structural mobility is of $19.5 \%$ and the replacement one is of $7.9 \%$ with a significant increase in the first one of 30 percentage points (49.5\%) and in the second one of 7 percentage points $(14.9 \%)$ in the change towards the intermediate cohort (1951-1975)_individuals who started their educational experience between 1958 and 1982_-(Table 3). It can be asserted that in the intermediate cohort the structure of educational mobility becomes less rigid through the reduction of the educational ascription understood as the influence of the origins on the educational destinies, and increasing the educational permeability due to a reduced reproduction accompanied by greater mobility opportunities. In the younger cohort (1976-1986) and in regard to the intermediate one, the educational mobility decreases 4.5 percentage points but it is still high in comparison to those recorded in the 
old cohort, while the replacement mobility increases 12.9 percentage points. Considering the intercohort incremental pattern of educational replacement mobility, which in contrast to the structural one offers a clearer view of the openness of the educational structure in terms of opportunities for educational mobility, it can be argued that it is in the young cohort where the better conditions take place in terms of greater educational permeability and lower rigidity in the structure of educational mobility (Table 3).

Table 3. Structural and replacement educational mobility

\begin{tabular}{|l|r|r|r|}
\hline Spain & $1935-1950$ & $1951-1975$ & $1976-1986$ \\
\hline Structural & $19.5 \%$ & $49.5 \%$ & $45.0 \%$ \\
Replacement & $7.9 \%$ & $14.9 \%$ & $27.8 \%$ \\
\hline
\end{tabular}

Source: Prepared by the author based on the ESS, 2010.

\section{Absolute educational mobility in Mexico \\ Educational Upward and Downward Mobility and Reproduction in Mexico}

In the analysis of the educational upward and downward mobility and reproduction between educational origins and destinies of Mexicans between 25 and 65 years old, it is observed that the educational upward mobility reaches $53.5 \%$, the downward mobility is of $3.6 \%$ and the reproduction reaches $42.8 \%$ (Table 4). From the records of these three dimensions incorporated in the analysis it may be concluded that Mexico presents an intergenerational educational mobility structure less fluid that the one observed for the Spanish case, with 57.2\% total absolute educational mobility rate conformed in its greatest part by movements towards higher educational positions (upward movements).

In the case of Mexican society the highest educational reproduction is registered between sons/daughters and parents below the lowest secondary level (ISCED 0-1) (31.1\%) (Table 4), constituting $72.6 \%$ of the total absolute volume of educational reproduction. Mexican and Spanish societies share the presence of a greater reproduction in the lowest educational level (ISCED 0-1), being slightly greater in the first country than in the second one: $31.1 \%$ and $22.6 \%$ respectively, thus constituting $72.6 \%$ and $64.4 \%$ of the total absolute volume of educational reproduction in each one respectively (Tables 1 and 4). In Mexico, as well as in Spain, it is at the tertiary educational level completed (ISCED 5-6) where the second higher proportion of inherited educational is recorded; in Mexico $4.9 \%$ (Table 4), equivalent to $11.4 \%$ of the total absolute volume of educational reproduction. In accordance with what has been observed, the educational inheritance is concentrated in the "polar" positions of the educational structure, configuring a sort of "fenced zones" of intergenerational reproduction of the educational positions at the base and the top of the structure, being the strongest the one at the base (ISCED 0-1) (Table 4). 
Comparative analysis of intergenerational educational mobility in Spain and Mexico

Table 4. Relation between parent and sons/daughters level of education (absolute and relative frequencies)

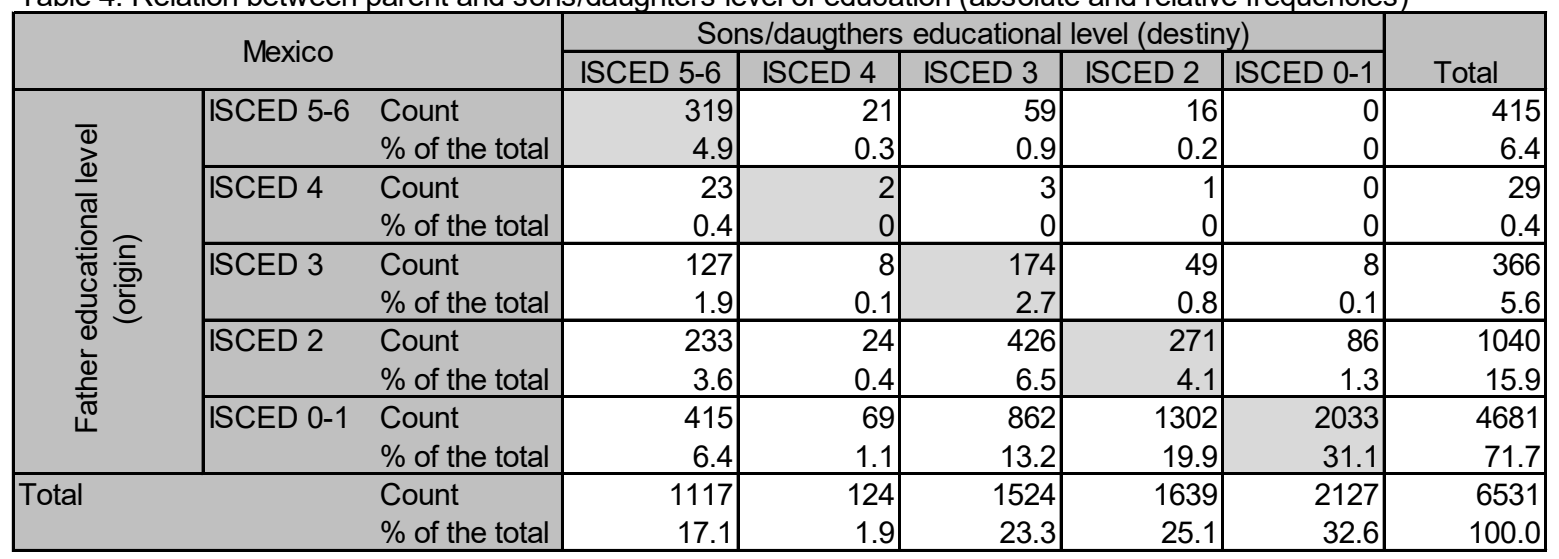

Source: Prepared by the author based on the EMOVI, 2011.

In relation to the upward mobility, data show that the sons/daughters of parents with an educational level of ISCED 0-1 are the ones who experience more upward mobility (40.6\%), equivalent to $75.9 \%$ of the total absolute volume of educational upward mobility. The record of a greater upward mobility experienced by sons/daughters with educational level of ISCED 0-1 is a shared observation by the Mexican and Spanish societies. The greater proportion of educational upward mobility experienced by the sons/daughters of parents with an educational level of ISCED 0-1 is recorded towards the proximate level of ISCED 2 (19.9\%) accounting for the $49 \%$ of the total absolute volume of educational upward mobility from the ISCED 0-1 origin (Table 4). Next, in contrast with the case of Spain, where the second higher proportion of upward mobility from the ISCED 0-1 takes place towards ISCED 5-6, is the upward mobility towards the higher secondary level completed ISCED $3(13.2 \%)$ the second higher, equals $32.5 \%$ of the total absolute volume of educational upward mobility from the educational origin ISCED 0-1 (Table 4). Summed together, the proportions of educational upward movements from the origin ISCED 0-1 towards the proximate educational destinies ISCED 2 and ISCED is of $33.1 \%$, which equaling to $81.5 \%$ of the total absolute volume of educational upward mobility from the ISCED 0-1.

Concerning educational downward mobility in Mexico, the greatest proportion is registered for the sons/daughters of parents with tertiary educational level completed (ISCED 5-6) (1.4\%), equivalent to $37.8 \%$ of the total absolute volume of educational downward mobility (Table 4). Next is the educational downward mobility experienced by the sons/daughters of parents with a secondary lower level completed (ISCED 2) (1.3\%), which constitutes $35.1 \%$ of the total absolute volume of educational downward mobility (Table 4). The data observed in the mobility table show that the greater proportion of downward mobility from the educational origin ISCED 5-6, takes place towards the educational destinies of the higher secondary level completed (ISCED 3) (0.9\%), which constitute $64.3 \%$ of the total absolute volume of educational downward mobility from the origin ISCED 5-6 (Table 4). The rest of the downward mobility from the origin ISCED 5-6 towards 
the rest of educational destinies presents notably reduced proportions. In a similar way to what was observed in the case of Spain, the downward mobility experienced by the sons/daughters of parents with an educational level of ISCED 5-6 towards the polar educational position in the opposite lowest extreme of the educational structure (ISCED 0-1) is non-existent (Table 4).

Upon analyzing the inflows of the educational mobility for Mexican society, it is observed that the probability for the sons/daughters to achieve the highest educational level of ISCED 5-6 is influenced by the educational level achieved by the parents, while there is no evidence of a positive relationship between this probability and the level of influence of the educational origins. In contrast, the analysis of the inflows shows that the probability for the sons/daughters to overcome the lowest educational levels (ISCED 0-1 and ISCED 2) is conditioned under a positive relation with the educational level reached by the parents, namely: the lower the educational level of the parent, the lower the probability for the sons/daughters to overcome the two lowest educational levels (Graphic II).

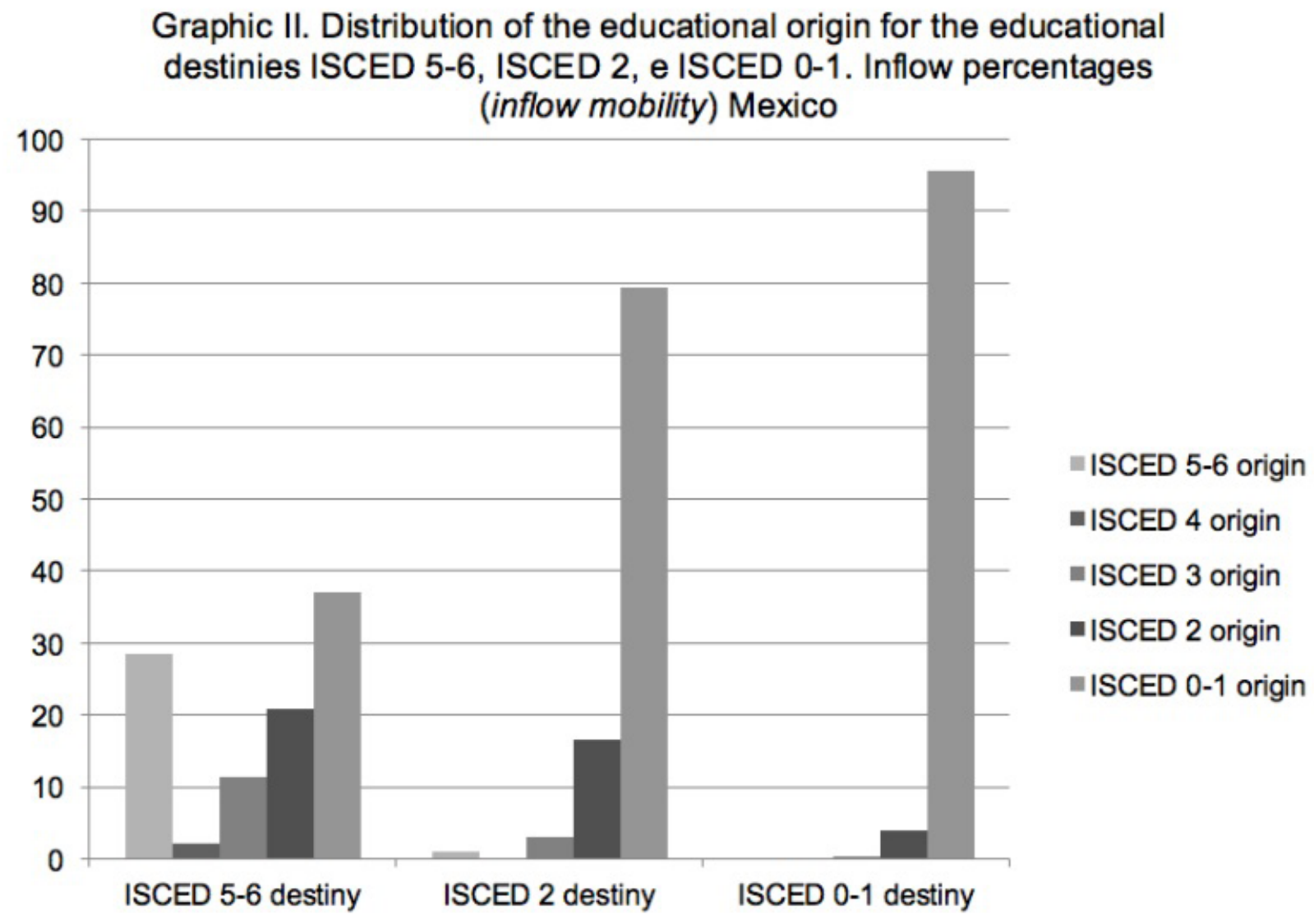

Source: Prepared by the author based on the EMOVI, 2011. 
Inter-Cohort Evolution of Educational Upward and Downward Mobility and Reproduction in Mexico

In the case of Mexican society there are three birth cohorts defined: an old cohort which gathers together individuals born between 1947 and 1960, who by $2011^{6}$ are between 64 and 51 years old, an intermediate cohort which gathers together individuals born between 1961 and 1975, who by 2011 are between 50 and 36 years old, and a young cohort which gathers together individuals born between 1976 and 1986, who by 2011 are between 35 and 25 years old. In the analysis of the educational upward and downward mobility and reproduction, after including the temporal factor through the variable of the birth cohorts, it is observed that in the old cohort (1947-1960), the educational reproduction is $64.1 \%$, the upward mobility $33.2 \%$ and the downward one $2.7 \%$ (Table5). Compared with the two younger cohorts the old one shows a higher level of educational reproduction, with an influence of the origins on the educational destinies in terms of inherited positions which turned out to be the strongest. The old cohort shows the lowest educational permeability in the inter-cohort evolution, with a total absolute educational mobility rate of $35.9 \%$

Table 5. Dimensions of educational absolute mobility

\begin{tabular}{|l|r|r|r|}
\hline Mexico & $1947-1960$ & $1961-1975$ & $1976-1986$ \\
\hline Inheritance & $64.1 \%$ & $39.5 \%$ & $35.6 \%$ \\
Upward & $33.2 \%$ & $57.8 \%$ & $59.1 \%$ \\
Downward & $2.7 \%$ & $2.7 \%$ & $5.2 \%$ \\
& $100.0 \%$ & $100.0 \%$ & $100.0 \%$ \\
\hline
\end{tabular}

Source: Prepared by the author based on the EMOVI, 2011.

In the intermediate cohort (1961-1975) and in relation to the old cohort, the educational reproduction (39.5\%) decreases 24.6 percentage points, 12.4 percentage points less than what it decreases in Spain for the same cohorts. The educational upward mobility (57.8\%) increases 24.6 percentage points, 12 percentage points less than what it increases in Spain for the same cohorts. The educational downward mobility remains constant (2.7\%) (Table 5). The proportion in which the educational reproduction decrease in the intermediate cohort in regard to the old cohort leads to a proportional increase of the upward mobility which does not have an impact on the educational downward mobility. As a consequence, the educational ascription in terms of inherited educational positions decreases while the educational permeability increases with a total absolute educational mobility rate going by the order of $60.5 \%$ (Table 5 ).

In relation to the youngest cohort (1976-1986) and as compared to the intermediate one, the educational reproduction decreases 3.9 percentage points, thus defining a decreasing inter-cohort reproduction pattern $(64.1 \%, 39.5 \%$ and $35.6 \%$, respectively); a trend which with difference as far Mexico.

${ }^{6}$ Year in which concludes the collection of information for the survey used for the analysis of social educational mobility in 
as magnitudes are concerned, is also observed in the Spanish society. The educational upward mobility in the young cohort, as compared to the intermediate cohort increases 1.3 percentage points, establishing an incremental inter-cohort educational upward mobility pattern $(33.2 \%, 57.8 \%$ and $59.1 \%$, respectively), which with difference as far as magnitudes are concerned is also shared by the Spanish society. In relation to the educational downward mobility (5.2\%), the constant pattern is interrupted by an increase of 2.5 percentage points (Table 5). The educational ascription decreases while the educational permeability increases, with a total absolute educational mobility rate of $64.3 \%$ (Table 5).

\section{Structural and Replacement Educational Mobility in Mexico}

As with the analysis of intergenerational educational mobility in Spain, in the study of intergenerational educational mobility in Mexico it is possible to differentiate between structural and replacement mobility. The structural educational mobility, which allows for an assessment of the degree of openness of the educational structure without isolating (controlling) the influence of changes in the educational and demographic structure on the movements between educational origins and destinies ISCED, is of 39.1\%, 7.4 percentage points less than the registered for the Spanish case (46.5\%) (Table 6). The replacement mobility, which contributes to the assessment of the degree of openness of the educational structure in terms of its capacity to reward the successful and unsuccessful practices in the competitiveness for the upward mobility to a higher educational destinies controlling the changes in the educational and demographic structure, is equal to $18.1 \%$, near to the one observed in the Spanish society (18.4\%) (Table 6). In a comparative perspective with the Spanish case, Mexico presents a higher level of educational ascription and a lower degree of permeability. In the Mexican educational stratification system, the educational origin is a stronger conditioning factor on the educational destiny than in the Spanish case.

Table 6. Structural and replacement mobility

\begin{tabular}{|l|r|r|}
\hline \multicolumn{2}{|c|}{ Spain } & \multicolumn{2}{c|}{ Mexico } \\
\hline Structural & 46.5 & 39.1 \\
Replacement & 18.4 & 18.1 \\
\hline
\end{tabular}

Source: Prepared by the author (ESS 2010 and EMOVI 2011).

\section{Inter-cohort Evolution of Structural and Replacement Educational Mobility in Mexico}

In the analysis of structural and replacement educational mobility for Mexican society after the inclusion of the temporal variable of birth cohorts, it is observed that in the old cohort (1947-1960), which gathers together individuals who started their educational experience between 1953 and 1967 , the structural mobility is $25.3 \%$ and the replacement one $10.6 \%$. In the intermediate cohort 
(1961-1975), which gathers together individuals who started their educational experience between 1968 and 1982, the structural mobility increases 19.1 percentage points (44.4\%) and the replacement one 6.5 point (17:1) (Table 7). It is possible to ascertain that in the intermediate cohort the conditioning of the educational origins on the destinies is reduced, while the inheritance of educational positions decreases and the opportunities for less rigidity of the structure of the educational mobility increase. In the young cohort (1976-1986) and in relation to the intermediate cohort, the structural educational mobility decreases 3.7 percentage points, although it remains higher than the one observed in the old cohort, while the replacement mobility is increased to 6.6 percentage points. In the inter-cohort comparison of the educational replacement mobility, accounting for the degree of openness of the educational structure in terms of the educational upward and downward mobility opportunities offered to the members of a society, it is confirmed that it is in the young cohort where the greatest degree of permeability and the lowest educational ascription take place (Table 7).

Table 7. Structural and replacement educational mobility

\begin{tabular}{|l|r|r|r|}
\hline Mexico & $1947-1960$ & $1961-1975$ & $1976-1986$ \\
\hline Structural & $25.3 \%$ & $44.4 \%$ & $40.7 \%$ \\
Replacement & $10.6 \%$ & $17.1 \%$ & $23.7 \%$ \\
\hline
\end{tabular}

Source: Prepared by the author based on the EMOVI, 2011.

\section{Relative Educational Mobility in Spain and Mexico}

The study of the relative educational mobility is based on the evaluation of a series of indicators which are applied in the comparative analysis among log-linear models. Among the indicators considered in this article are the statistical of the likelihood ratio $\mathrm{L}^{2}$, in which associated probability is taken as proof of hypothesis, where null hypothesis ( $\mathrm{H} 0)$ affirms the existence of a fit between the theoretical mobility model and the observed data in the educational mobility table. The alternate hypothesis (H1) confirms the existence of a mismatching given the existence of significant statistical differences between the expected data with the applied theoretical model and the observed data in the educational mobility table. The null hypothesis is adopted when the probability associated to the statistical $\mathrm{L}^{2}$ is greater than or equal to $5 \%(\alpha \geq 0.05)$, thus satisfying the principle of sufficiency (existence of likelihood ratio of the theoretical model).

If the null hypothesis is adopted the next step consists in evaluating the degree of adequacy of the theoretical model in relation to the observed data based on the comparison with the baseline model. The model which by definition is used as reference is the so called saturated model. This is the theoretical model that best fit the data as it satisfies the principle of sufficiency and at the same time the least parsimonious by applying all the fitting parameters to the available data. Consequently, it is possible to adopt as reference model the so called conditional independence model, 
which formulates the hypothesis of the existence of statistic independence between the educational origins and destinies, that is, the existence of the perfect educational mobility, an ideal situation which does not have a counterpart in the observed reality in the society. When the conditional independence model is adopted as reference and the theoretical model applied presents a likelihood ratio $\mathrm{L}^{2}$ and a number of freedom degrees lower than that of the reference (conditional independence model), it can be concluded that the model is more parsimonious and better fit than the reference one, thus the most suitable. In addition to satisfying the sufficiency principle, the selected model must satisfy the principle of simplicity or parsimony, according to which the model that accounts for the characteristics of the data through the lowest possible number of parameters is the one that better fit the observed data. The method followed to evaluate the adequacy of the models is based in gradually calculating the differences between the likelihood ratios $\mathrm{L}^{2}$ of the models that are compared to each other as well as in relation to the reference model.

The analysis is complemented by the integration of a set of indicators that reinforce the accuracy of the comparative evaluation of the theoretical models of educational mobility. It is therefore possible to count on more information than the one offered by the statistical of likelihood ratio $\mathrm{L}^{2}$ in order to make decisions about the grade of fitting and the adequacy of the observed data of educational mobility. One of these indicators is the so called Bayesian Information Criterion (BIC) which contributes to evaluating the verisimilitude relation between two compared models. The less the BIC value of a model, the better it satisfies the principle of simplicity. A second complementary indicator in the evaluation of the models is the dissimilarity D index, which synthesizes the discrepancy level between the distribution of the observed data and that of the expected one under the applied theoretical model. The dissimilarity D index informs about the proportion of cases which ought to be reclassified in order to achieve the situation of statistic independence, so that the lower the value recorded by the index the better the adjustment of the model to the observed data.

A third complementary indicator which is useful in the comparative evaluation of the educational mobility models is the Goodman's coefficient of multiple determination pseudo $\mathrm{R}^{2}$. The coefficient shows the capacity of the theoretical model to account for the observed associations among the analyzed variables. The higher the value of Goodman's pseudo $\mathrm{R}^{2}$ the better the theoretical method explains the observed data. Finally, a fourth complementary indicator in the comparative evaluation of models is the Schwartz' standardizer $\mathrm{L}^{2}(\mathrm{~S})$. The standardizer shows a relation among more than two variables at the same time, and by normalizing the relation improves the measurement carried out by the statistical of the likelihood ratio $\mathrm{L}^{2}$, which tends to be sensible to the size of the sampling. The value of the Schwartz' standardizer $\mathrm{L}^{2}(\mathrm{~S})$ is used as proof of hypothesis of the likelihood ratio $\mathrm{L}^{2}$, so that interpretation of its associated probability by adopting the null hypothesis can be determined, as long as it is equal to or greater than a $5 \%$ or 0.05 level of significance.

In the analysis of the intergenerational relative educational mobility in Mexican and Spanish societies, the variables of educational origins $(\mathrm{O})$ (the parents educational level), the educational 
destinies (D) (the sons/daughters educational level) and the birth cohorts (C) are all placed in relation. The models to be evaluated are the conditional independence, the constant fluidity (CnSF), and the uniform difference (unidiff) model. The conditional independence model is assumed as the reference one in the evaluation of the level of fitting of the constant fluidity model. In the case of Spain, the model of conditional independence shows a likelihood ratio $L^{2}$ equals 365,563 for 48 degrees of freedom with an associated probability (Sig.) lower than 5\% (Table 8). When the likelihood ratio $\mathrm{L}^{2}$ is normalized by the Schwartz' standardizer it decreases to 131,569 with a still lower than $5 \%$ associated probability. Additionally, the model presents a dissimilarity D index equals $15.6 \%$ and a BIC value of 13.30 , both of them showing the highest values among the compared models. Consequently, the mismatching of the conditional independence model with the observed data is concluded, thus it does not satisfy the principles of sufficiency and parsimony. The rejection of the model is equivalent to affirming that there exists conditioning of the educational origins on the destinies.

The constant fluidity model, which proposes the hypothesis of the existence of an educational reproduction mobility pattern that is constant through time, from one generation to another, presents a value of likelihood ratio $\mathrm{L}^{2}$ equals 15,793 for 32 degrees of freedom, with a higher than $5 \%$ associated probability (Sig.) (Table 8). With a value of BIC equals -219.05 , below the one registered for the conditional independence model, and the lowest dissimilarity D index in the comparison between models $(1.9 \%)$, the constant fluidity model explains $95.7 \%$ better the observed data than the conditional independence one (Table 8 ). When the likelihood ratio $\mathrm{L}^{2}$ of the constant fluidity model is normalized by the Schwartz standardizer, it comes to 27,735 for 32 degrees of freedom, with an associated probability (Sig.) higher than 5\% (Table 8). Consequently, the fit of the constant fluidity model to the data observed is concluded, satisfying the sufficiency and simplicity principles-being the most parsimonious among the compared models-and accepting the hypothesis of the existence of an educational mobility and reproduction pattern which remains invariant from one cohort to another.

If the constant fluidity model proposes the hypothesis of the existence of an educational mobility and reproduction pattern which remains constant along time, the model of the uniform difference (unidiff) $)^{7}$ formulates the hypothesis of the existence of a monotonous pattern (uniform change) between educational origins and destinies when the generations (cohorts) are compared, thus allowing to estimate the strength of the educational fluidity/rigidity. The model of the uniform difference is useful to endorse or qualify the hypothesis of the existence of a constant educational mobility pattern formulated by the constant fluidity model. The unidiff model shows a likelihood ratio $\mathrm{L}^{2}$ equals 43,200 for 45 degrees of freedom with an associated probability (Sig.) higher than $5 \%$ (Table 8). When the likelihood ratio $\mathrm{L}^{2}$ is normalized by the Schwartz' standardizer, it increa-

\footnotetext{
${ }^{7}$ The uniform association values instead of full interaction values are considered in the analysis of the unidiff model.
} 
ses to 44,526, with an associated probability (Sig.) higher than 5\% (Table 8). With the lowest BIC value of all compared models (-287.5), a dissimilarity D index equals 3.5\% and explaining the observed data $88.2 \%$ better than the conditional independence model, it can be concluded that the uniform difference model fits the observed data in the educational mobility table. Therefore, the hypothesis of the existence of a uniform change pattern between educational origins and destinies along the cohorts is accepted.

\begin{tabular}{|c|c|c|c|c|c|c|c|c|}
\hline Models & $\mathrm{L}^{2}$ & $\begin{array}{c}\text { Degree of } \\
\text { freedom }\end{array}$ & Sig. & BIC & Pseudo $\mathrm{R}^{2}$ & $\begin{array}{c}\text { Dissimilarity } \\
\text { index }\end{array}$ & $L^{2}(\mathbf{S})$ & Sig. $L^{2}(S)$ \\
\hline \multicolumn{9}{|c|}{ Origins, Destinies and Cohorts } \\
\hline Saturated model [O D C] & 0.000 & 0 & 1.000 & 0.00 & $100.00 \%$ & $0.0 \%$ & 0.000 & 1.000 \\
\hline Condicional Indep. [O C] [D C] & 365.563 & 48 & 0.000 & 13.30 & $0.00 \%$ & $15.6 \%$ & 131.569 & 0.000 \\
\hline Constant fluid [O D] $[\mathrm{O} C][\mathrm{D} \mathrm{C}]$ & 15.793 & 32 & 0.993 & -219.05 & $95.68 \%$ & $1.9 \%$ & 27.735 & 0.682 \\
\hline Unidiff & 43.200 & 45 & 0.550 & -287.05 & $88.18 \%$ & $3.5 \%$ & 44.526 & 0.491 \\
\hline
\end{tabular}

Having accepted the uniform difference model, the next step is to interpret the beta $(\beta)$ coefficients or phi $(\varphi)$ parameters offered by the model in the interest of observing the behavior of the relative educational mobility in terms of variability along the cohorts and the degree of educational rigidity-fluidity which characterizes the pattern. Taking the old cohort of the individuals born between 1935 and 1950 as the reference cohort, one observes the existence of a pattern of low variability towards the intermediate cohort (1951-1975) (coefficient equals 0.9149) and a pattern of greater variability towards the young cohort (1976-1986) (coefficient equals 0.6823), where a sharp intensification of the educational fluidity can be confirmed (Table 9). Considering the limitations of working with only three cohorts, the behavior of the educational fluidity pattern shows a low variability between the two older (old and intermediate cohorts) and a sharp variability towards the youngest one. A pattern is confirmed which establishes that the educational fluidity among cohorts increases-coefficient values below 1 indicate fluidity, while values higher than 1 indicate rigidity-and is intensified in the youngest one (1976-1986).

Table 9. Educational relative mobility (Spain)

Phi parameters (Unidiff)

\begin{tabular}{|l|c|}
\hline Cohorts & Parameters \\
\hline Born between 1935-50 & 1.0000 \\
Born between 1951-1975 & 0,9149 \\
Born between 1976-86 & 0,6823 \\
\hline
\end{tabular}

Source: Prepared by the author based on the European Social Survey, 2010. 
The analysis of relative educational mobility for the case of Mexico shows a model of conditional independence with a value of likelihood ratio $\mathrm{L}^{2}$ equals 2125,298 for 48 degrees of freedom and an associated probability (Sig.) lower than 5\% (Table 10). Upon normalizing the likelihood ratio $\mathrm{L}^{2}$ by the Schwartz' standardizer it is reduced to 460.851 for 48 degrees of freedom, with an associated probability (Sig.) lower than 5\%. With a value of BIC and a dissimilarity D index of 1703.65 and $19.8 \%$, respectively, which are the highest among the compared models, it can be asserted that the conditional independence model does not satisfy neither the principle of sufficiency nor the parsimony one, so it is concluded that there is a mismatching between the theoretical model and the observed data. It can be affirmed that there is significant statistical association between educational origins and destinies.

The analysis of the educational fluidity based on the constant fluidity model records a likelihood ratio $\mathrm{L}^{2}$ equals 121.337 , for 32 degrees of freedom with an associated probability (Sig.) lower than $5 \%$ (Table 10). Even though the constant fluidity model shows values of BIC and dissimilarity D index (-159.76 and 2.7\%, respectively) that are amongst the lowest in the comparison and explain the observed data $94.3 \%$ better than the conditional independence model, it is concluded that it does not satisfy the sufficiency principle as it does not fit the observed data (Table10). The nonexistence of an invariant educational mobility and reproduction pattern through the birth cohorts in Mexican society can be affirmed.

The uniform difference model (unidiff) shows a likelihood ratio $\mathrm{L}^{2}$ equals 370.800 for 45 degrees of freedom, with an associated probability (Sig.) lower than 5\% (Table 10). When the statistical of likelihood ratio $\mathrm{L}^{2}$ is normalized by the Schwarz standardizer it is reduced to 109,751 , for 45 degrees of freedom and an associated probability (Sig.) lower that 5\% (Table 10). With a BIC equals -24.49 , a dissimilarity D index of $7 \%$ and explaining the observed data $82.6 \%$ better than the conditional independence model, the model of uniform difference does not satisfy the sufficiency and parsimony principles. The unidiff model does not fit the observed data in the educational mobility table, so the non-existence of a uniform change pattern between educational origins and destinies through the generations (cohorts) can be affirmed.

Table 10. Educational relative mobility. Log-linear models (Mexico)

\begin{tabular}{|l|r|r|r|r|r|r|r|r|}
\hline \multicolumn{1}{|c|}{ Models } & $\mathbf{L}^{2}$ & $\begin{array}{c}\text { Degree of } \\
\text { freedom }\end{array}$ & \multicolumn{1}{c|}{ Sig. } & BIC & Pseudo $\mathbf{R}^{2}$ & $\begin{array}{c}\text { Dissimilarity } \\
\text { index }\end{array}$ & $\mathbf{L}^{2}$ (S) & Sig. $\mathbf{L}^{2}(\mathbf{S})$ \\
\hline Origins, Destinies and Cohorts & & & & & & & & \\
\hline Saturated model [O D C] & 0.000 & 0 & 1.000 & 0.00 & $100.0 \%$ & $0.0 \%$ & 0.000 & 1.000 \\
\hline Condicional Indep. [O C] [D C] & 2125.298 & 48 & 0.000 & 1703.65 & $0.0 \%$ & $19.8 \%$ & 460.851 & 0.000 \\
\hline Constant fluid [O D] [O C] [D C] & 121.337 & 32 & 0.000 & -159.76 & $94.3 \%$ & $2.7 \%$ & 49.755 & 0.023 \\
\hline Unidiff & 370.800 & 45 & 0.000 & -24.49 & $82.6 \%$ & $7.0 \%$ & 109.751 & 0.000 \\
\hline
\end{tabular}

Source: Prepared by the author based on the EMOVI, 2011. 


\section{Conclusions}

Based on the comparative analysis of the intergenerational educational mobility in Spain and Mexico, the following findings can be synthetized. In relation to the analysis of the absolute educational mobility in terms of educational upward and downward mobility and reproduction for individuals between 25 and 65 years old, Spanish society is different from the Mexican society inasmuch as it presents a lesser inheritance of educational positions ( 7.7 percentage points less), a greater educational upward mobility (6.8 percentage points greater) and a downward mobility of only 0.9 percentage points. The results speak of lower educational ascription levels and higher educational permeability in the Spanish society in relation to Mexican society with total absolute educational mobility rates of $64.9 \%$ and $57.2 \%$, respectively. The obtained findings are consistent with those reached by Mediavilla and Calero (2010), in which analysis a clean positive relation can be observed between parents' education (origins) and the educational level achieved by sons/daughters (destinies); relation that the authors find milder in the Spanish case than in the Mexican one, accompanied by an intergenerational educational mobility that proves to be higher in the first one. ${ }^{8}$

The Spanish case shares with the Mexican one a record of the greater proportion of the total absolute volume of educational reproduction in the lower educational level (ISCED 1-0), however, the educational reproduction observed in the Mexican society is stronger. Furthermore, both societies share the fact that the second greater proportion of the volume of total absolute educational reproduction takes place in the highest educational level (ISCED 5-6), being the strongest the one observed in Spain. It is observed in both societies that the educational reproduction tends to concentrate at the top and at the base of the educational structure, being more intense the one that concentrates at the base than at the top and in Mexico the tendency is still stronger than in Spain. The results point at the greater advantages which in both societies have the individuals whose parents have completed a higher university education. In this sense, the educational upward mobility, when the educational origin is ISCED 0-1-strong in both societies-is a sort of short distance mobility (upward movements of just only one position or level ahead) to a proximate level of destiny ISCED 2 in both countries. However, in Spain a high proportion of extended distance educational upward mobility also takes place (upward movements from the lowest to the highest level in the educational structure) from the ISCED 0-1 origin to ISCED 5-6 destiny, while in the case of Mexico the high proportion refers to a mobility of large distance kind (upward movements of two or three educational levels or positions) from an ISCED 0-1 origin to an ISCED 3 destiny. This means that in Spanish society there are greater probabilities than in Mexico to access to and complete a university education coming from parents who have a maximum level of complete primary education. As

${ }^{8}$ Mediavilla and Calero (2010) find a correlation which is equal to 0.552 between the parent's educational level and that of their sons/daughters for the Mexican society while the level obtained for the Spanish society is 0.42 (Carabaña, 1999), 0.45 (Sánchez, 2004) and 0.43 (Calero and Escardíbul, 2005). The greater the value of the correlation coefficient, the greater the educational rigidity of the society under study. 
far as educational downward mobility is concerned, the greater proportion of downward mobility takes place from the educational origin ISCED 5-6-the most elevated taking place in the case of Spain-which is associated to possible ceiling effects, as there is not a higher educational category (level) than ISCED 5-6 to aim to and, in contrast, a handful to which it is possible to descend.

When the absolute educational mobility is analyzed including the temporal factor of the cohorts variable, it is confirmed that both societies share a decreasing inter-cohort educational reproduction pattern, with a significant decreasing "leap" from the old cohort to the intermediate one of 37 percentage points in the Spanish case and of 24.6 in the Mexican one, which is in turn reduced from the intermediate cohort towards the young one, with 8.4 points less in the case of Spain and 3.9 in the case of Mexico. Educational upward mobility shows an incremental inter-cohort pattern in both societies. In Spain, the incremental "leap" of the educational upward mobility is of 36.6 percentage points from the old cohort to the intermediate, while in Mexico it is of 24.6 points for the same cohorts. As far as the educational downward mobility, its incremental "leap" goes from the intermediate to the young cohort. Therefore, it can be affirmed that the educational downward mobility will increase once the upward mobility (through increasing) and the educational reproduction (through decreasing) are stabilized. A first conclusion can be made that of the three edges of the absolute educational mobility which are analyzed (educational reproduction, upward and downward mobility), the differences between the Spanish and the Mexican societies refer to magnitudes while the similarities refer to the temporal trends.

In the case of Mexico, the variations that come off as positive (reduction of the educational reproduction, increase of the educational upward mobility and constant educational downward mobility) from the old cohort to the intermediate are explained by educational trajectories of the individuals born between 1961 and 1975, experienced by the end of the sixties and during the seventies and eighties in a context of educational expansion that started to fade out due to the economic crisis and the reduction of the social expense in education that took place during the eighties. The impact of these changes is still incipient on the intermediate cohort, but evident for the individuals of the young one (1976-1986), who experienced their educational trajectories towards the end of the eighties and during the nineties, in a context of slowdown of the reduction of the educational reproduction as of the increase of the educational upward mobility. The crisis and the structural adjustment in the Mexican society had an effect on the educational achievement of the individuals of the young cohort. These results are consistent with Torche's (n.d.), Binder (1999) and Binder and Woodruff (2002) findings which reinforce the thesis of an educational stagnancy of the cohort of individuals who experienced their educational trajectory in the Mexican context of economic crisis. In the case of Spain, and in contrast to Mexico, a greater inter-cohort reduction of the educational reproduction is observed, as well as a greater increment of the total absolute educational mobility rate, a finding that is consistent with the results reached by Mediavilla and Calero (2010), who calculate the index of educational immobility for Mexico, which is 0.39 , against 0.18 of Spain 
(Mediavilla and Calero, 2006), concluding the existence of a lower relative educational mobility and an educational system which reproduces with greater strength the initial social disadvantages in the Latin American country against the European one.

The analysis of the relative educational mobility by the application of three log-linear models (conditional independence, constant fluidity and uniform difference), allows to conclude that in the Spanish society, unlike in the Mexican society, there is an educational mobility and reproduction pattern that remains unchanged from one generation to another, being the young cohort (19761986) the one showing a greater educational fluidity, which is also observed, even if reduced, in the intermediate one (1951-1975). In the case of the Mexican society it is possible to affirm the non-existence of an educational mobility and reproduction pattern which remains constant from one generation to another. These findings in Mexican society are consistent with Torche's observation who, through the application of the uniform difference and constant fluidity models concludes that the change in the educational mobility pattern in Mexico is weak with predominance of temporal stability. The analysis of the relative educational mobility developed in this article would be reinforced with the future integration of log-linear models like the proposed by Hout (1983) that hypothesizes the existence of a "closed circuit" in the highest and lowest levels of the educational structure, suggesting the existence of a very narrow educational mobility, the Hauser's model (Hauser, 1978) that hypothesizes the existence of greater rigidity and reproduction in the lowest educational levels in relation to the higher ones, where a greater educational fluidity would take place, and the cross model proposed by Powers and Xie (2000) that states that the probability of an individual experiencing educational mobility from one level to another is determined by the degree of difficulty of crossing the barriers that separate these levels.

\section{Bibliography}

Beyer, H. y C. Le Foulon (2002). "Un recorrido por las desigualdades salariales en Chile". En: Estudios Públicos, núm. 85, pp. 139-175.

Binder, M. (1999). "Schooling indicators during Mexico's 'Lost Decade"'. En: Economic Education Review, núm. 18, pp. 183-199.

- y C. Woodruff (2002). "Inequality and intergenerational mobility in schooling: The case of Mexico" En: Economic Development and Cultural Change. Vol. 50, núm. 2, pp. 249-267.

Birdsall, N. y J. L. Lodoño (1998). "No tradeoff: Efficient growth via more equal human capital accumulation”. En: C. Birdsall, N., C. Graham y R. Sabot (eds.). Beyond tradeoffs: Make reform and equitable growth in Latin America. Washington: IADB.

Boado, M. (2008). "La movilidad social en el Uruguay contemporáneo". Tesis doctoral. Río de Janeiro: Instituto Universitario de Pesquisas de Río de Janeiro, IUPERJ-UDELAR. 
Calero, J. (2006). "Desigualdades tras la educación obligatoria: Nuevas evidencias". Documento de Trabajo de la Fundación Alternativas, núm. 83.

— y J. O. Escardíbul (2005). "Financiación y desigualdades en el sistema educativo y de formación profesional en España”. En: Navarro, V. (ed.). La situación social de España. Madrid: Biblioteca Nueva-Fundación Largo Caballero, pp. 337-384.

— S. Waisgrais y M. Mediavilla (2007). "Desigualdades socioeconómicas en el sistema educativo español”. Colección Investigación del CIDE, núm. 176.

— y Á. Quiroga (2008). Sociedad desigual ¿Educación desigual? Sobre las desigualdades en el sistema educativo español. Colección Investigación del CIDE, núm. 7.

Carabaña, J. (1999). Dos estudios sobre movilidad intergeneracional. Madrid: Fundación Argentaria-Visor.

Cragg, M. y M. Epelbaum (1996). "Why has wage dispersion grown in Mexico? Is it the incidence of reforms or the growing demand for skills?". En: Journal of Development Economics, núm. 51, pp. 99-116.

Duryea, S. y C. Pages (2002). "Achieving high labor productivity in Latin America: Is education enough?”. Washington: IADB, mimeo.

Escobar Latapí, A. (1993). "Reestructuración económica y desigualdad social en México: el caso de Guadalajara". Ponencia presentada al Primer Congreso Latinoamericano de Sociología del Trabajo. El Colegio de México, noviembre de 1993.

- (1995). "Movilidad, restructuración, y clase social en México. El caso de Guadalajara". En: Estudios Sociológicos. Vol. 13, núm. 38, pp. 309-339.

- y Fernando Cortés (2002). "Modelos de acumulación de capital y movilidad social: un estudio del México urbano". México: Mimeo.

Filgueira, C. (2001). "La actualidad de viejas temáticas: sobre los estudios de clase, estratificación y movilidad social en América Latina". En: Serie Políticas Sociales de la CEPAL, núm. 51.

Goldthorpe, J. H. (1980) Social mobility and class structure in modern Britain. Oxford: Clarendon. Hauser, R. (1978). "Some exploratory methods for modelling mobility tables and other crossclassified data". En: CDE Working Paper, núm. 19.

Hout, M. (1983). Mobility tables. Beverly Hills: Sage.

Martínez-Celorrio, X. y A. Marín Saldo (2010). Educació i mobilitat social a Catalunya. Barcelona: Fundació Jaume Bofill.

Mediavilla, M. y J. Calero (2006) "Movilidad educativa en España. Un análisis con datos del PHOGUE". En: Investigaciones de Economía de la Educación, núm. 1, pp. 25-34.

- (2010). "Movilidad educativa en Latinoamérica, un estudio para seis países". En: Revista Española de Educación Comparada, núm. 16, pp. 287-303.

Powers, D. e Y. Xie (2000). Statistical methods for categorical data analysis. San Diego: Academic Press. 
Psacharopoulos, G. y H. Patrinos (2002). Returns to investment in education: A further update. World Bank Policy Research Paper, núm. 2881.

Ricardi, A. (2012) "Movilidad educativa en España. Modelos explicativos y perspectiva comparada". Tesis de maestría en investigación sociológica. Barcelona, Departamento de Teoría Sociológica, Filosofía del Derecho y Metodología de las Ciencias Sociales, Universidad de Barcelona.

- (2014) "Bases para el estudio comparativo de la movilidad social sobre una selección de sociedades democráticas Europa y América Latina". En: IXAYA, núm. 7, pp. 13-46.

- (2016) "Panorama reciente del bienestar en México: reformas y estrategias de desarrollo en perspectiva comparada". En: Revista Vínculos, núm. 8.

Robbins, D. (1995). Trade, trade liberalization and inequality in Latin America and East Asia: Synthesis of seven country studies. Cambridge: Harvard University.

Sánchez, A. (2004). "Movilidad intergeneracional de ingresos y educativa en España 1980-1990". Documento de trabajo del Institut d'Economia de Barcelona, núm. 2004/1.

Torche, F. (2007). "Movilidad intergeneracional y cohesión social: Análisis comparado de Chile y México". Documento preparado para el Proyecto Nascal, Cieplan-iFHC, octubre de 2007.

- (n.d.). "Movilidad intergeneracional en México: Primeros resultados de la encuesta ESRU de Movilidad Social en México". Consultado por última vez el 15 de agosto de 2015 en: http://www.ceey.org.mx/pdf/Movilidad\%20Social/MovilidadSocial_Torche_MovilidadMexico.pdf 